\title{
Learning Strategies to Engage in Quality Interactions Online
}

\author{
Chun-Ying Chen \\ Center for General Education, National Taichung University of Education \\ 140 Minsheng Road, Taichung, 40306, Taiwan \\ E-mail: cychen666@gmail.com
}

Received: December 3, 2013 Accepted: December 18, 2013 Published: December 19, 2013

doi:10.5296/jet.v1i1.4661 URL: http://dx.doi.org/10.5296/jet.v1i1.4661

\begin{abstract}
This study examined students' learning strategies to engage in quality interactions in asynchronous online discussions via computer conferencing. Quality interaction in this study was defined as students being able to construct knowledge by engaging in active interactions with others and deep information processing. This study used a mixed-method design and two data sources: observations of online discussions and semi-structured interviews. Observations of online discussions were used to identify active deep processors. Then interviews were conducted with the active deep processors to explore their strategy use. The findings identified several learning strategies contributing to students' quality interactions in computer conferencing. Those strategies included online class preparation strategies, strategies to identify relevant information, strategies to process information in computer conferencing, strategies to process printed materials, strategies to keep learning on track, strategies to organize learning, and strategies to avoid internal and external distractions. The results revealed the importance of metacogntive awareness in achieving both quality and quantity level of interaction in online learning.
\end{abstract}

Keywords: online discussions, computer conferencing, learning strategies, cognitive strategies, metacognitive strategies, affective strategies

\section{Introduction}

Computer conferencing (CC) is a popular cognitive tool to foster knowledge construction through the development of discourse communities in online learning. While conferencing, learners are electronically engaged in discussion and interaction with peers and experts in a process of social negotiation; knowledge construction occurs when they explore issues, take positions, discuss those positions in an argumentative format, and reflect on and re-evaluate 
their positions (Jonassen, Davidson, Collins, Campbell, \& Haag, 1995). CC's capacity for developing quality learning depends on the availability of long periods of learner-controlled reflection time, peer interaction through continual discussions, active cognitive engagement, and an effective collaborative group environment (Moore, 2002; Schellens \& Valcke, 2006).

While CC is acknowledged as a powerful medium to engage learners in academic discourse for knowledge construction in online learning, the issue of promoting quality interactions in $\mathrm{CC}$ appears to be complex. Quality learning or interaction in online discussions has been defined differently in various studies. The most common operational definitions include cognitive presence (Kanuka, Rourke, \& Laflamme, 2007; Garrison \& Cleveland-Innes, 2005), critical thinking (Angeli, Valanides, \& Bonk, 2003; Newman, Webb, \& Cochrane, 1995; Perkins \& Murphy, 2006), and higher level thinking (Gunawardena, Lowe, \& Anderson, 1997). Considering CC from constructivist perspectives, quality interaction in this study was defined as students being able to construct knowledge by engaging in active interactions with others and deep level of information processing. Various studies have attempted to investigate variables that influence the quality of online discussions (for a review, see Spatariu, Quinn \& Hartley, 2007). These variables include instructional methods (Kanuka et al., 2007), moderating strategies (Angeli et al., 2003; Salmon, 2000), course structure, and leadership (Garrison \& Cleveland-Innes, 2005). This study investigated the importance of another concern: learning strategies.

\section{Theoretical Framework}

\subsection{Quality Learning in Computer Conferencing}

Typically in online learning, instructors deliver courses entirely via the Web, along with a CC system for interactive activities. Usually the course website consists of self-instructional learning materials and ongoing interaction and communications between the instructor and students take place in CC. While the instructor posts relevant resources on the Web for the class, students access and manipulate information deemed relevant to the learning goals of the course. This process, which demands their cognitive engagement through self-interaction with course content to engender learning, empowers students to be active learners. Learning can also occur in online discussions via $\mathrm{CC}$, which is often acknowledged as a conversation medium for knowledge construction from a constructivist perspective (Jonassen et al., 1995). On the surface, online discussions provide an opportunity for the instructor to see students' participation in the class. Practically, students' knowledge construction can occur in online discussions through interaction with peers or the instructor.

Constructivist conceptions of learning assume that knowledge is individually constructed and socially co-constructed by students based on their interpretation of experiences and prior knowledge structures (Jonassen, 1999). Knowledge construction is achieved by the interaction that takes place within oneself in the form of an internal dialogue (i.e., reflective thought) and by the interaction that occurs in communications and collaboration with other people (Vygotsky, 1978) in online discussions via CC. Computer conferencing therefore can promote quality learning, which occurs through deep reflective thinking and interaction with others (Bannan-Ritland, 2002; Berge, 2002; Moore, 2002). Studies in classroom settings have 
showed the influence of several variables inherent in students on quality learning. The variables that may influence levels of information processing include students' study approaches, affective dimension, learning orientation, and the amount of invested mental effort put into study. Studies showed that a deep approach (Entwistle \& Waterston, 1988; Marton \& Säljö, 1984; Watkins, 1983), an absence of anxiety and intrinsic motivation (Entwistle \& Waterston; Fransson, 1977), and more mental effort put into study (Salomon, 1983) contribute to a deep level of information processing.

Quality learning can also be achieved by active learning through interaction with other people. Interaction in this study refers to learner-learner and learner-teacher interactions. Interaction is regarded as a critical component of the educational process. Bates (1995) noted that if a major rationale for $\mathrm{CC}$ is to encourage and develop the skills of academic discourse, active participation from all students is important; however, it can be argued that in a face-to-face teaching environment, many students do not participate actively, yet often learn. It is not clear from research that interaction improves learning in most distance education programs (Kearsley, 1995). Nevertheless, interaction may lead to learner satisfaction, which in turn contributes to motivation. Cheng, Lehman, and Armstrong (1991) reported a higher completion rate for those online learners who worked collaboratively $(90 \%)$ than for those who worked independently (22\%) in CC classes. In their teletraining instruction, Martin and Bramble (1996) found that students typically preferred to interact with the instructor, fellow students, and the instructional media by asking questions and having discussions rather than to listen to a lecture or have limited involvement and interaction.

\subsection{Learning Strategies}

Whereas research indicates that study approaches may affect students' quality of learning, this section is devoted to addressing techniques that students use during learning. Literature in the field of psychology offers many methods of categorizing learning strategies (Olgren, 1998; Tessmer \& Jonassen, 1988; Weinstein \& Mayer, 1986). In general, learning strategies can be collapsed into three broad categories: cognitive strategies, metacognitive strategies (Olgren, 1998; Weinstein \& Mayer, 1986), and affective strategies (Weinstein \& Mayer, 1986).

\subsubsection{Cognitive Strategies}

Cognitive strategies encompass selection strategies, rehearsal strategies, elaboration strategies, and organizational strategies (Olgren, 1998; Weinstein \& Mayer, 1986). These strategies aim at assisting learners cognitive processes to construct knowledge and facilitate later recall. Students use selection strategies such as external and internal focusing to direct their attention and to differentiate relevant from irrelevant information (Olgren, 1998). External focusing refers to students identifying important information based on external means such as learning objectives, overviews/outlines provided in the course, and course requirements. Internal focusing is based on students' own needs, goals, and interests (Olgren, 1998). Selection strategies are necessary because the human information processing system has a limited processing capacity. 
Students use rehearsal strategies to help them remember what they learn. Examples include repeating, reading aloud, reviewing, copying, or underlining only the important parts of a lesson. Rehearsal strategies are usually regarded as rote learning strategies because students memorize information by simple repetition or reproduction. Understanding can enhance the ability to remember learning materials (Olgren, 1998).

Elaboration and organizational strategies that aim at understanding play an important role in deep and effective learning. Elaboration strategies help students understand new information. Students then link the new information to their prior knowledge. Visualizing, associating, summarizing, creating metaphors, and paraphrasing are common examples of elaboration strategies (Olgren, 1998; Weinstein \& Mayer, 1986).

Organizational strategies help students understand and remember the given information by translating it into another form and building connections within the information given. Students use organizational strategies to divide information into different groups based on shared attributes and to indicate the relationship among those groups (Weinstein \& Mayer, 1986). Classifying, diagramming, comparing, contrasting, and creating a concept map, a hierarchy, or an outline are common examples of organizational strategies. Whereas elaboration and organizational strategies are regarded as deep approaches, rehearsal strategies are regarded as surface approaches (Olgren, 1998).

\subsubsection{Metacognitive Strategies}

Metacognitive strategies assist students in guiding and monitoring their cognitive processes. There are two types of metacognitive strategies - orienting and regulating strategies (Olgren, 1998). Orienting strategies include identifying required tasks, appraising the relevance or usefulness of the tasks, estimating the mental effort involved, establishing goals, and making a study plan to prepare for learning. A common example of these techniques is students' preparation for learning by using the instructor's syllabus for information about course objectives, expectations, and requirements.

Regulating strategies are used to monitor cognitive processes. Checking comprehension, monitoring time and pacing, adapting cognitive strategies to learning demands, revising goals, persisting until tasks are completed, seeking help, and self-testing to evaluate what was learned are common examples of regulating strategies. Metacognitive strategies are directed at regulating the cognitive and affective strategies and therefore indirectly lead to learning results (Vermunt, 1996).

\subsubsection{Affective Strategies}

Affective strategies are used to create and maintain an individual's emotional status and a suitable environment for learning. They include strategies that students use to focus attention, maintain concentration, manage anxiety, establish and maintain motivation, and manage time effectively (Weinstein \& Mayer, 1986). Examples of affective strategies are using relaxation and positive self-talk to reduce anxiety, reducing environmental distractions by finding a quiet place to study, establishing priorities, and setting a schedule. Affective strategies may be the most effective for information selection and acquisition (Weinstein \& Mayer, 1986). 


\subsection{Analytical Framework for Quality Interactions}

Henri's (1992) method was used as a framework to assess the quality of students' contributions to online discussions that was characterized by a deep level of information processing and active interaction with others. The analytical framework suggested five dimensions of learning process for analysis in terms of participation, interaction, social presence, cognitive skills, and metacognitive skills. Her methods of evaluating cognitive skills of surface or deep processing within students' messages and students' participation and interaction suited our research purpose.

A number of methods are available for the evaluation of quality of online discussions. Given the varying purposes of the research studies for which they were developed, these methods naturally differ from one another. However, they all tend to evaluate the same three phenomena: participation, social interactivity, and cognitive/metacognitive processes or critical thinking. Several investigators have applied Henri's method for the evaluation of online discourse (e.g., Guan, Tsai, \& Hwang, 2006; Gunawardena et al., 1997; Hara, Bonk, \& Angeli, 2000; Newman et al., 1995). Henri's method was selected because it provides a wide range of analytical dimensions which can best support our research purpose. Her analytical framework was further modified so that the quality learning in $\mathrm{CC}$ can be assessed most appropriately. The modification is described in the method section.

\section{Research Questions}

This study was designed to examine students' strategy use to engage in quality interaction (characterized by a deep level of information processing and active interaction with others) in asynchronous online discussion via computer conferencing. Three questions guided this research:

(1) What level of information processing do students exhibit in their discussion messages, surface or deep processing?

(2) What kinds of interaction patterns do students exhibit when they participate in online discussions?

(3) What learning strategies do students employ to engage in active interactions and deep level of information processing?

\section{Methods}

\subsection{Online Courses and Participants}

Two online classes at a large university in the United States were selected. The instructional context of each class included a website and a CC system. The conferencing system offered the non-linear structure of threaded discussions in which each topic is the starting point for a branch of responses. The learning activities required in the two classes were similar: both included small-group discussions, individual projects and critiques, and final papers. Participants were 12 graduate students from the two online classes. Of the 12 participants (five females and seven males), one-half were master's students and one-half were doctoral 
students. Five participants were full-time students, whereas seven were employed full-time. Students with different ranges of experience with technology use and online courses were selected purposefully.

\subsection{Data Collection and Analysis}

This study used a mixed-method design and two data sources: observations of online discussions and semi-structured interviews. The first data source was used to answer question one and two. Then the combined results of questions 1 and 2 were used to identify students who engaged in quality learning through deep information processing and interaction with others. Those who met the necessary criteria (i.e., the depth of processing ratio was beyond 0.70 and a pattern of two interactions or above two interactions was exhibited) were identified as students engaged in quality learning. Those students' learning strategies were examined in order to answer the third question through interviews. The semester-long classes lasted a total of 16 weeks. All participants' messages in online discussions during the whole semester were collected for analysis. Semi-structured interviews then were conducted with the selected participants who were identified as active deep processors near the end of the semester.

\subsubsection{Observations of Online Discussions}

To answer question one and two, Henri's (1992) analysis framework for evaluating cognitive skills of surface or deep processing within students' messages and students' interaction was used. To analyze surface or deep information processing, Henri's framework for analyzing levels of information processing was used as the coding protocol. The framework identified two levels of information processing: surface processing and deep processing. The indicators for surface-level processing were (a) repeating oneself without further elaboration or adding new information, (b) making supporting comments or acknowledgements without further elaboration, (c) offering information without evidence of elaboration or justification, (d) asking irrelevant questions, and/or (e) demonstrating fragmentary understanding. The indicators for deep processing include (a) linking facts and ideas, (b) offering new information, (c) proposing solutions with justification, (d) discussing the tradeoffs involved in a situation or solution, (e) making judgments supported by justification or examples, and/or (f) presenting a wider perspective.

After analyzing surface and deep processing, then Newman et al.'s (1995) approach was applied to convert each participant's total counts of surface and deep processing into a depth of processing ratio for comparison. The unit of analysis was a paragraph. $\mathrm{X}+$ was used to indicate total units of deep processing, whereas X- was used to indicate total units of surface processing for each participant. A depth of processing ratio was calculated for each participant using the formula $(\mathrm{X}+-\mathrm{X}-) /(\mathrm{X}++\mathrm{X}-)$, converting the counts to a -1 (all surface) to +1 (all deep) scale.

To observe interaction patterns, a modified version of Henri's (1992) method of evaluating interaction was used. The unit of analysis was a posting. Henri proposed three types of interactive process: explicit, implicit, and independent. An explicit process refers to a direct 
response to or a comment on a specific message or student. An implicit process refers to an indirect response or a commentary in which the content of another student's message is mentioned, but not that person's name. An independent process is a posting that stands alone without referring to any other messages or students. Simply counting the three interactive processes proposed by Henri does not provide enough information to analyze students' interactivity. By observing the combination of interactive processes exhibited by each participant for a particular discussion question, varied interaction patterns occurred: "no interaction," "one interaction only," "two interactions," and "above two interactions."

- "No interaction" pattern: This pattern was defined as "0 $0 \quad \mathrm{X}$," where X refers to any number. This pattern occurred when the discussion participant posted no explicit/implicit messages at all and/or any number of independent messages.

- "One interaction" pattern: This pattern was defined as " $10 \mathrm{X}$ ”, and " $01 \mathrm{X}$," where $\mathrm{X}$ refers to any number. This pattern occurred when the discussion participant posted one explicit/implicit message and/or any number of independent messages.

- "Two interactions" pattern: This pattern was defined as "2 $0 \mathrm{X}$," "1 $1 \mathrm{X}$," and "0 $2 \mathrm{X}$," where $\mathrm{X}$ refers to any number. This pattern occurred when the discussion participant posted two explicit/implicit messages and/or any number of independent messages.

- "Above two interactions" pattern: Otherwise, the pattern was defined as "above two interactions." This pattern occurred when the discussion participant posted more than two explicit/implicit messages and/or any number of independent messages.

To explain by example how these coding procedures are presented, a sample matrix using mock data to display interaction patterns was generated (Table 1). Table 1 shows distribution of each interactive process for each student grouped by the discussion questions. There were two units in all; each unit contained two discussion questions. A total of 5 students (Don, Jessica, Daniel, Tony, and Sally) participated in the discussions. For example, for discussion question 1 in the first unit, Don posted 1 explicit message, 0 implicit messages, and 0 independent messages, and therefore generated the "one interaction" pattern ("1 00 "). His interaction pattern for discussion question 2 in the first unit was the "above two interactions" pattern (“3 01 1”).

After each participant's interaction patterns were coded, the number of times each interaction pattern was exhibited by each participant was determined. Participants' totals for each interaction pattern were then used to determine their level of involvement with others when learning in online discussions. 
Table 1. A Sample Matrix Using Mock Data to Display Interaction Patterns

\begin{tabular}{|c|c|c|c|c|c|c|c|}
\hline \multirow{2}{*}{ Discussion Unit } & \multirow{2}{*}{$\begin{array}{c}\text { Discussion } \\
\text { Question }\end{array}$} & \multirow{2}{*}{ Interactive Process } & \multicolumn{5}{|c|}{ Student } \\
\hline & & & Don & Jessica & Daniel & Tony & Sally \\
\hline \multirow{6}{*}{ Unit 1} & \multirow{3}{*}{ Q1 } & Explicit & 1 & 0 & 2 & 3 & 2 \\
\hline & & Implicit & 0 & 0 & 0 & 0 & 1 \\
\hline & & Independent & 0 & 1 & 1 & 1 & 2 \\
\hline & \multirow{3}{*}{ Q2 } & Explicit & 3 & 0 & 1 & 0 & 3 \\
\hline & & Implicit & 0 & 0 & 1 & 0 & 0 \\
\hline & & Independent & 1 & 0 & 3 & 1 & 1 \\
\hline \multirow{6}{*}{ Unit 2} & \multirow{3}{*}{ Q1 } & Explicit & 1 & 0 & 2 & 3 & 1 \\
\hline & & Implicit & 0 & 0 & 1 & 0 & 0 \\
\hline & & Independent & 1 & 1 & 1 & 1 & 0 \\
\hline & \multirow{3}{*}{ Q2 } & Explicit & 1 & 0 & 1 & 1 & 3 \\
\hline & & Implicit & 0 & 0 & 1 & 0 & 0 \\
\hline & & Independent & 2 & 0 & 3 & 1 & 1 \\
\hline
\end{tabular}

Notes. Explicit $=$ a direct response to or a comment on a specific message/student.

Implicit $=$ an indirect response or comment in which the content of another student's message was mentioned, but not that person's name.

Independent $=$ a message that stood alone without referring to any other messages/students, or a message that answered the discussion question.

"No interaction" pattern $=$ " $00 \mathrm{X} "$ ( $\mathrm{X}$ refers to any number).

"One interaction" pattern = "1 $0 \mathrm{X}$, , and " $01 \mathrm{X}$ " (X refers to any number).

"Two interaction" pattern = "2 $0 \mathrm{X}, "$ "1 $11 \mathrm{X}$, , and "0 $2 \mathrm{X}$ " (X refers to any number).

"Above two interactions" pattern = patterns other than "no interaction," "one interaction," and "two interactions." 


\subsubsection{Semi-structured Interviews}

Interviews were used to examine the answers to the third question by exploring the selected participants' strategy use in online learning. The interview questions were open ended questions about learning experiences both in online discussions and on the course website. The interviewees were guided to talk about their learning experiences in front of a computer where the participants had access to the online class they were taking. In doing so, the effects of distortion or memory loss were assumed to be minimal.

All interview transcript analysis was consistent with the constant comparative method (Lincoln \& Guba, 1985). The constant comparative method is an inductive data analysis, which uses the specific raw data of transcripts to generate abstract categories. The analysis took the form of successive iterations involving the procedures based on Lincoln and Guba's techniques of unitization and categorization. The iterations were repeated until no new patterns emerged. Data collection and analysis continued until the categories were saturated (i.e., definitions of categories were well defined). To ensure credibility of the findings, i.e., the trustworthiness of the data (Lincoln \& Guba, 1985), extensive member checking with the interviewees was conducted throughout the study.

\section{Results}

\subsection{Levels of Information Processing in Online Discussions}

The analysis of the online discussion transcripts showed that all students exhibited both deep and surface processing. The depth of processing ratio for each student was further calculated for group comparison. Students who engaged in deep learning were those whose depth of processing ratio was beyond 0.70 . They were placed in the Deep group. Other students were placed in the Surface group. The results of the calculation divided the 12 participants into two groups (Table 2). Using Henri's (1992) model as a guide, it may be concluded that the students processed information superficially based on their use of six of the eight indicators of surface processing:

- they repeated what was said without further elaboration or without offering new information;

- they posted compliments, agreements, or supportive comments without further elaboration;

- they offered solutions or judgments without evidence of elaboration or justification; and

- they demonstrated fragmentary understanding of the course contents by giving wrong interpretations or injecting unreliably equivocal knowledge without indicating their sources as justification. 
Table 2. Levels of Information Processing Exhibited in Online Discussions

\begin{tabular}{|c|c|c|c|c|c|}
\hline $\begin{array}{c}\text { Group } \\
(n=12)\end{array}$ & $\begin{array}{c}\text { Total \# of } \\
\text { messages }\end{array}$ & $\begin{array}{c}\text { Total \# of } \\
\mathrm{X}^{+}\end{array}$ & Total \# of $\mathrm{X}^{-}$ & $\begin{array}{c}\text { Average } \\
\text { depth of } \\
\text { processing } \\
\text { ratio }\end{array}$ & Range \\
\hline $\begin{array}{c}\text { Deep } \\
(n=5)\end{array}$ & 142 & 175 & 22 & 0.80 & $0.70 \sim 0.88$ \\
\hline $\begin{array}{c}\text { Surface } \\
(n=7)\end{array}$ & 120 & 85 & 59 & 0.11 & $-0.52 \sim 0.50$ \\
\hline
\end{tabular}

Notes. $\mathrm{X}^{+}=$total units of deep processing and $\mathrm{X}^{-}=$total units of surface processing.

The depth of processing ratio indicates a -1 (all surface) to +1 (all deep) scale.

\subsection{Online Interaction}

Students in both Deep and Surface groups exhibited varied interaction patterns including "no interaction", "one interaction only", "two interactions", and "above two interactions", as indicated in Table 3. Overall, there was no big difference for the interaction patterns exhibited between the two groups, but slightly more students in the Deep group exhibited both "two interactions" and "above two interactions" patterns. However, students in the Deep group tended to participate more as compared to the Surface group (averagely 28.4 messages per student to 17.1).

Table 3. Mean Percentages for Each Interaction Pattern Exhibited in Online Discussions

\begin{tabular}{|l|l|l|l|l|l|}
\hline \multirow{2}{*}{$\begin{array}{l}\text { Group } \\
(n=12)\end{array}$} & $\begin{array}{l}\text { avg \# of messages } \\
\text { per person }\end{array}$ & \multicolumn{4}{|c|}{ Type of Interaction Pattern } \\
\cline { 3 - 6 } & $\begin{array}{l}\text { No } \\
\text { Interaction }\end{array}$ & $\begin{array}{l}\text { One } \\
\text { Interaction }\end{array}$ & $\begin{array}{l}\text { Two } \\
\text { Interactions }\end{array}$ & $\begin{array}{l}\text { Above Two } \\
\text { Interactions }\end{array}$ \\
\hline $\begin{array}{l}\text { Deep } \\
(n=5)\end{array}$ & 28.4 & $16.0 \%$ & $14.9 \%$ & $8.8 \%$ & $14.5 \%$ \\
\hline $\begin{array}{l}\text { Surface } \\
(n=7)\end{array}$ & 17.1 & $11.1 \%$ & $20.2 \%$ & $5.7 \%$ & $8.8 \%$ \\
\hline
\end{tabular}




\subsection{Strategy Use to Engage in Quality Interactions Online}

Students who engaged in deep processing were those whose depth of processing ratio was beyond 0.70 . Students who engaged in active learning through interaction with others were those who exhibited the pattern of two interactions or above two interactions. Only four out of 12 participants met the necessary criteria for identification as students engaged in quality learning. Strategies those active deep processors used to engage in online learning were categorized as: strategies to identify relevant information, strategies to process information in $\mathrm{CC}$, strategies to process printed materials, online class preparation strategies, strategies to keep learning on track, strategies to organize learning, and strategies to avoid internal and external distractions. The former three categories belong to the cognitive dimension of learning strategies (summarized in Table 4). The last one category belongs to the affective dimension and others are the metacognitive dimension of learning strategies (summarized in Table 5).

Table 4. Cognitive Dimension of Learning Strategies Reported by Active Deep Processors

\begin{tabular}{|l|l|}
\hline Category & Strategies \\
\hline Relevant Information & $\begin{array}{l}\text { (1) Identify messages to read that deal with personal interests, } \\
\text { or commentary involving different perspectives or } \\
\text { contradictories. }\end{array}$ \\
& $\begin{array}{l}\text { (2) Identify which students usually post more meaningful } \\
\text { messages and learn from them. }\end{array}$ \\
$\begin{array}{l}\text { To discern relevant materials to study: } \\
\text { (3) Refer to introductions, overviews, and learning objectives } \\
\text { for the units in order to gain a general understanding of the } \\
\text { materials and to identify specific materials on which to focus. } \\
\text { Then, refer to assignments to determine which materials to } \\
\text { study. }\end{array}$ \\
\hline Strategies to Process \\
Information in CC & $\begin{array}{l}\text { (1) Use the "message summarize" feature offered by CC for } \\
\text { unread messages, taking each major thread separately. } \\
\text { (2) Close irrelevant subfolders or limit the number of subfolders } \\
\text { open in CC to avoid confusion. } \\
\text { (3) Forward discussion messages to a personal e-mailing } \\
\text { system, if unaccustomed to reading messages in CC. And } \\
\text { manage messages there by using functions of the e-mailing }\end{array}$ \\
\hline
\end{tabular}




\begin{tabular}{|l|l|}
\hline & system that are familiar. \\
\hline $\begin{array}{l}\text { Strategies to Process } \\
\text { Printed Materials }\end{array}$ & $\begin{array}{l}\text { (1) Highlight important keywords, definitions, and ideas when } \\
\text { reading articles in order to help remember the important parts } \\
\text { and obtain an overview. } \\
\text { (2) Apply note-taking skills acquired in on-site classroom } \\
\text { learning. Although time-consuming, the process of note-taking } \\
\text { enhances understanding and saves time later on when doing } \\
\text { assignments. }\end{array}$ \\
\hline
\end{tabular}

Table 5. Metacognitive/Affective Dimensions of Learning Strategies Reported by Active Deep Processors

\begin{tabular}{|c|c|}
\hline Category & Strategies \\
\hline $\begin{array}{l}\text { Online class } \\
\text { preparation strategies }\end{array}$ & $\begin{array}{l}\text { (1) To resolve technological problems: } \\
\text { (2) Consult online software manuals. } \\
\text { (3) Consult "Help" or the Q\&A conference provided by the } \\
\text { class. } \\
\text { (4) Ask friends or the instructor for help. } \\
\text { (5) To become familiar with how the course was structured and } \\
\text { how to perform the various CC tasks: } \\
\text { (6) Become familiar with and identify any questions/problems } \\
\text { from the course structure and the syllabus before the orientation } \\
\text { session. } \\
\text { (7) Attend the orientation session in order to understand the } \\
\text { course structure and the syllabus, obtain necessary technical } \\
\text { skills, and resolve any questions/problems. Orientation results in } \\
\text { a readiness for content learning. } \\
\text { (8) Practice working in the online environment. } \\
\text { (9) Ask or observe peers online when unsure how to do a task. }\end{array}$ \\
\hline $\begin{array}{l}\text { Strategies to Keep } \\
\text { Learning on Track }\end{array}$ & $\begin{array}{l}\text { (1) Look at peers' assignments. } \\
\text { (2) Find learning partners. Consult or discuss with them on the } \\
\text { phone, in person, or by e-mail to help understand any difficult } \\
\text { materials. }\end{array}$ \\
\hline
\end{tabular}




\begin{tabular}{|l|l|}
\hline & $\begin{array}{l}\text { (3) Interact with peers in online discussions and learn from } \\
\text { them. }\end{array}$ \\
\hline $\begin{array}{l}\text { Strategies to } \\
\text { Organize Learning }\end{array}$ & $\begin{array}{l}\text { (1) Set up a study plan for doing course work online and } \\
\text { offline. } \\
\text { (2) Create a personal calendar to keep track of upcoming } \\
\text { assignments. Or print out the unit syllabus containing } \\
\text { assignment due dates and requirements as a tracking system to } \\
\text { help keep up with the pace of instruction. }\end{array}$ \\
\hline $\begin{array}{l}\text { Strategies to Avoid } \\
\text { Internal and External } \\
\text { Distractions }\end{array}$ & $\begin{array}{l}\text { (1) Set up a schedule for study and completely focus on } \\
\text { studying during the time allotted. Adhere to this schedule and try } \\
\text { not to stay up too late or to become stressed out about unfinished } \\
\text { work. } \\
\text { (2) Manage one's personal emotional status (and keep on track } \\
\text { in the course) by reducing the potential for frustration or anxiety. } \\
\text { (3) Avoid external distractions (stemming from job and/or } \\
\text { family obligations) by finding a suitable place-such as a } \\
\text { library-for concentrating on studying. }\end{array}$ \\
\hline
\end{tabular}

\section{Discussion and Conclusion}

This study examined students' strategy use to engage in quality interaction (characterized by a deep level of information processing and active interaction with others) in asynchronous online discussion via $\mathrm{CC}$. The findings identify several learning strategies contributing to students' quality interactions in CC. Learning strategies those students used to engage in active interactions (i.e., those who were likely to post the pattern of two interactions or above two interactions) and deep level of information processing (i.e., those whose information processing ratio was beyond 0.70 ) were categorized as: strategies to identify relevant information, strategies to process information in $\mathrm{CC}$, strategies to process printed materials, online class preparation strategies, strategies to keep learning on track, strategies to organize learning, and strategies to avoid internal and external distractions. The former three categories belong to the cognitive dimension of learning strategies. The last one category belongs to the affective dimension and others are the metacognitive dimension of learning strategies. The results thus offer suggestions to instructors on teaching relevant learning strategies, and to students on using those learning strategies, for promoting deep and meaningful learning in $\mathrm{CC}$.

It was observed that not all deep processors were active learners who exhibited the pattern of two interactions or above two interactions. On the other hand, not all active learners engaged in deep processing in online discussions. Although these kinds of cases were just a few in this 
study, further investigation is needed to examine the relationship between the levels of information processing and interactions online.

The important contribution of this study was to reveal the importance of metacogntive awareness in achieving both quality and quantity level of interaction in online discussions. In addition to cognitive strategies that are typically regarded as a hallmark of deep learning, the active deep processors used a variety of metacognitive and affective strategies (i.e., online class preparation strategies, strategies to keep learning on track, strategies to organize learning, and strategies to avoid internal and external distractions). The strategies used by those students demonstrated their metacognitive awareness of the importance of preparing, monitoring, regulating, and evaluating their learning in order to accomplish the learning goals. This observation was in line with Vermunt's (1996) findings showing that students who are mostly self-regulated tend to display deep processing. The results of this study tended to support Biggs' claims that metacognitive strategies lead to improvements in academic performance; in other words, for success in learning "students need to be aware of their motives, of task demands, and of their own cognitive resources, and to exert control over the strategies appropriate for handling the task" (1988, p. 127).

\section{References}

Angeli, C., Valanides, N., \& Bonk, C. J. (2003). Communication in a web-based conferencing system: The quality of computer-mediated interactions. British Journal of Educational Technology, 34(1), 31-43. http://dx.doi.org/10.1111/1467-8535.00302

Bannan-Ritland, B. (2002). Computer-mediated communication, eLearning, and interactivity: A review of the research. Quarterly Review of Distance Education, 3(2), 161-179.

Bates, A. W. (1995). Technology, open learning, and distance education. London: Routledge.

Berge, Z. L. (2002). Active, interactive, and reflective eLearning. Quarterly Review of Distance Education, 3(2), 181-190.

Biggs, J. (1988). The role of metacognition in enhancing learning. Australian Journal of Education, 32(2), 127-138. http://dx.doi.org/10.1177/000494418803200201

Cheng, H., Lehman, J., \& Armstrong, P. (1991). Comparison of performance and attitude in traditional and computer conferencing classes. American Journal of Distance Education, 5(3), 51-64. http://dx.doi.org/10.1080/08923649109526763

Entwistle, N., \& Waterston, S. (1988). Approaches to studying and levels of processing in university students. British Journal of Educational Psychology, 58, 258-265. http://dx.doi.org/10.1111/j.2044-8279.1988.tb00901.x

Fransson, A. (1977). On qualitative differences in learning: IV-Effects of motivation and test anxiety on process and outcome. British Journal of Educational Psychology, 47, 244-257. http://dx.doi.org/10.1111/j.2044-8279.1977.tb02353.x

Garrison, D. R., \& Cleveland-Innes, M. (2005). Facilitating cognitive presence in online learning: Interaction is not enough. American Journal of Distance Education, 19(3), 133-148. 
http://dx.doi.org/10.1207/s15389286ajde1903_2

Guan, Y.-H., Tsai, C.-C., \& Hwang, F.-K. (2006). Content analysis of online discussion on a senior-high-school discussion forum of a virtual physics laboratory. Instructional Science, 34(4), 279-311. http://dx.doi.org/10.1007/s11251-005-3345-1

Gunawardena, C. N., Lowe, C. A., \& Anderson, T. (1997). Analysis of a global online debate and the development of an interaction analysis model for examining social construction of knowledge in computer conferencing. Journal of Educational Computing Research, 17(4), 397-431. http://dx.doi.org/10.2190/7MQV-X9UJ-C7Q3-NRAG

Hara, N., Bonk, C. J., \& Angeli, C. (2000). Content analysis of online discussions in an applied educational psychology course. Instructional Science, 28(2), 115-152. http://dx.doi.org/10.1023/A:1003764722829

Henri, F. (1992). Computer conferencing and content analysis. In A. R. Kaye (Ed.), Collaborative learning through computer conferencing: The Najaden papers (pp. 115-136). New York: Springer-Verlag. http://dx.doi.org/10.1007/978-3-642-77684-7_8

Jonassen, D. (1999). Designing constructivist learning environments. In C. M. Reigeluth (Ed.), Instructional design theories and models: A new paradigm of instructional theory (Vol. 2, pp. 215-239). Mahwah, NJ: Erlbaum. http://dx.doi.org/10.1080/08923649509526885

Jonassen, D., Davidson, M., Collins, M., Campbell, J., \& Haag, B.B. (1995). Constructivism and computer-mediated communication in distance education. The American Journal of Distance Education, 9(2), 7-26.

Kanuka, H., Rourke, L., \& Laflamme, E. (2007). The influence of instructional methods on the quality of online discussions. British Journal of Educational Technology, 38(2), 260-271. http://dx.doi.org/10.1111/j.1467-8535.2006.00620.x

Kearsley, G. (1995). The nature and value of interaction in distance learning. George Washington University, Washington, DC. Retrieved from http://www.gwu.edu/ etl/interact.html. Accessed 20 July 2002

Lincoln, Y. S., \& Guba, E. G. (1985). Naturalistic inquiry. Newbury Park, CA: Sage.

Marton, F., \& Säljö, R. (1984). Approaches to learning. In F. Marton, D. J. Hounsell, \& N. J. Entwistle (Eds.), The experience of learning (pp. 36-55). Edinburgh, UK: Scottish Academic Press.

Moore, M.G. (2002). What does research say about the learners using computer-mediated communication in distance learning? American Journal of Distance Education, 16(2), 61-64. http://dx.doi.org/10.1207/S15389286AJDE1602_1

Newman, D. R., Webb, B., \& Cochrane, C. (1995). A content analysis method to measure critical thinking in face-to-face and computer supported group learning. Interpersonal Computing and Technology, 3(2), 56-77.

Olgren, C. H. (1998). Improving learning outcomes: The effects of learning strategies and 
motivation. In C. C. Gibson (Ed.), Distance learners in higher education: Institutional responses for quality outcomes (pp. 77-95). Madison, WI: Atwood.

Perkins, C., \& Murphy, E. (2006). Identifying and measuring individual engagement in critical thinking in online discussions: An exploratory case study. Educational Technology \& Society, 9(1), 298-307.

Salmon, G. (2000). E-moderating: The key to teaching and learning online. London, UK: Kogan Page. http://dx.doi.org/10.1080/00461528309529260

Salomon, G. (1983). The differential investment of mental effort in learning from different sources. Educational Psychologist, 18(1), 42-50.

Schellens, T., \& Valcke, M. (2006). Fostering knowledge construction in university students through asynchronous discussions groups. Computers \& Education, 46(4), 349-370. http://dx.doi.org/10.1016/j.compedu.2004.07.010

Spatariu, A., Quinn, L. F., \& Hartley, K. (2007). A review of research on factors that impact aspects of online discussions quality. TechTrends, 51(3), 44-48. http://dx.doi.org/10.1007/s11528-007-0041-9

Tessmer, M., \& Jonassen, D. (1988). Learning strategies: A new instructional technology. In D. Harris (Ed.), World yearbook of education 1988: Education for the new technologies (pp. 29-47). New York: Nichols.

Vermunt, J. D. (1996). Metacognitive, cognitive, and affective aspects of learning styles and strategies: A phenomenographic analysis. Higher Education, 31, 25-50. http://dx.doi.org/10.1007/BF00129106

Vygotsky, L. S. (1978). Mind in society: The development of higher psychological processes. Cambridge, MA: Harvard University.

Watkins, D. (1983). Depth of processing and the quality of learning outcomes. Instructional Science, 12, 49-58. http://dx.doi.org/10.1007/BF00120900

Weinstein, C. E., \& Mayer, R. E. (1986). The teaching of learning strategies. In M. C. Wittrock (Ed.), Handbook of research on teaching (3rd ed., pp. 315-327). New York: Macmillan.

\section{Copyright Disclaimer}

Copyright reserved by the author(s).

This article is an open-access article distributed under the terms and conditions of the Creative Commons Attribution license (http://creativecommons.org/licenses/by/3.0/). 